\title{
THE SOCIAL COST OF LABOR AND PROJECT EVALUATION: A GENERAL APPROACH
}

\author{
Raaj Kumar SAH \\ Yale University, New Haven, CT06520, USA \\ Joseph E. STIGLITZ* \\ Princeton University, Princeton, NJ 08540, USA
}

Received November 1983, revised version received March 1985

\begin{abstract}
This paper presents a general framework for analyzing shadow wages in LDCs. We focus on (i) the differences between the domestic and international prices, (ii) the equilibrating mechanisms in the economy, (iii) the endogeneity of earnings in industry and agriculture, (iv) the consequences of industrial employment creation on agriculture, and (v) the nature of migration and unemployment.

We identify those reduced form relationships which are central in determining the shadow wage, and use them to obtain general formulae for the shadow wage. These formulae can be specialized to alternative technological, behavioral, and institutional settings. This yields many new results concerning the relationship between the shadow wage and the market wage. Also, earlier results on shadow wages are derived as special cases of our formulae.
\end{abstract}

\section{Introduction}

During the past two decades, there has been a growing consensus both on the usefulness of social cost-benefit analysis for project and expenditure evaluation in developing economies, and on the general procedures by which shadow prices should be determined. If a new project is viewed as a perturbation in the economy, then its consequences (and hence the shadow prices) depend critically on the salient features of the economy. For instance, if the economy is open to foreign trade and there are tariffs, then the induced changes in domestic demand and supply of goods affect the public revenue from tariffs. If, on the other hand, the economy is closed, then there are general equilibrium changes in domestic prices which, in turn, affect the welfare of various individuals in the economy. It is important, therefore, to identify the relevant structure of the economy.

*An earlier version of this paper was released as the National Bureau of Economic Research Working Paper No. 1229, Cambridge, 1983. We thank two anonymous referees for their useful comments. 
The fact that we are interested in social cost-benefit analysis indicates a belief that market prices may not accurately reflect social costs, that is, there are some important distortions in the economy which need to be explicitly identified. Moreover, reasonable individuals may differ over the appropriate social welfare function and, hence, on the appropriate social weights (which should be associated with the gains and losses to different individuals and to the government) to be employed in aggregating the full consequences of a project. Therefore, the role of social weights in determining shadow prices needs to be clearly distinguished from the role of the critical structural features of the economy.

This paper focuses on shadow wage determination, ${ }^{1}$ and it makes two contributions. First, it emphasizes certain features of the economy which have important consequences for the shadow wage in many LDCs, but which have not received the attention they deserve. Among them arc the internal structure of the agricultural and the industrial sectors, the international trade environment, and the mechanism which equilibrates the economy to the perturbation caused by the new project. (Our modelling of these features is discussed below.) Second, we develop a framework to identify those reduced form parameters which capture the impact that various critical features of the economy have on the shadow wage. ${ }^{2}$ Our formulae for the shadow wage can, therefore, be specialized to a variety of technological, behavioral and institutional hypotheses.

Indeed, one of the lessons that has been learned in the past two decades is that there is enormous diversity within LDCs, and a set of specific assumptions which may be appropriate for one country will not be appropriate for others. That is precisely why it is important to construct a general framework, which includes as special cases all of the commonly discussed hypotheses. We, therefore, do not argue here whether there is or is not industrial unemployment; whether the level of industrial unemployment is or is not affected by employment decisions in the industrial sector; whether migration of agricultural workers to the industrial sector is or is not well described by the Harris-Todaro hypothesis; whether there is surplus land or surplus labor in the agricultural sector; whether the agricultural population is relatively homogenous or there are wide disparities within this population; whether the government does or does not set tariffs at optimal levels. Instead, we show how the same formulae for the shadow wage can be specialized to these and other hypotheses, and examine what implication this has, in turn, on the magnitude of the shadow wage.

We derive a number of new results concerning the qualitative relationship between the shadow wage and the market wage. Many of these results are

\footnotetext{
${ }^{1}$ Though our models can be easily employed to analyze pricing and taxation in LDCs [see Sah and Stiglitz $(1983,1984 a, 1984 b)]$ as well as the determinants of other shadow prices.

${ }^{2}$ These parameters, in principle, can be estimated.
} 
robust; that is, they are valid for a wide range of underlying parameter values. The importance of robustness lies in the fact that obtaining the precise numerical estimates for some of the critical parameters is often difficult. In addition, we have been able to synthesize the previous work on shadow wages, and to obtain previously known results as particular specializations of our more general approach. This synthesis helps to identify the precise sources of difference among the existing results.

The main components of our framework are the following.

(i) The structure of the agricultural sector. The creation of industrial employment often induces migration of agricultural workers to the industrial sector. The effect of this migration on the shadow wage is determined, in part, by how the welfare of those who remain in the agricultural sector is influenced by the general equilibrium consequences of migration on agricultural prices, wages and earnings. These, in turn, depend on the institutional mechanisms which allocate land, work, and output among various individuals within the agricultural sector. Consider a simple example. If agricultural wages rise due to migration, then the (net) sellers of labor (landless workers and small landowners) gain, while the net buyers of labor (large landlords) lose. If the society is averse to inequality then, in this case, there may be a net social gain which would reduce the magnitude of the shadow wage. We capture these effects in a model of an agricultural sector with heterogeneous individuals in which the distribution of earnings is endogenously determined.

(ii) The industrial sector. It has recently been argued that there are important relationships between the wages paid to the industrial workers and their net output. Several alternative explanations of such relationships have been offered; wages may affect the quality of a firm's applicant pool, the efficiency with which a given worker works, or the workers' turnover rates. We represent the industrial sector in a manner that exhibits these effects. Our formulation is consistent with many alternative wage determination mechanisms, including those which take into account wage-productivity relationship.

(iii) The migration of labor between sectors. The literature thus far has focused primarily on two cases: where there is no endogenous migration or where the migration is governed by a Harris-Todaro type hypothesis. Our general model of migration subsumes these two cases. Also, our determination of the shadow wage takes into account many of the general equilibrium effects of endogenous migration which have often been ignored in earlier studies.

(iv) Foreign trade environment. Most studies on the shadow wage assume an open economy in which there are no deviations between the domestic and the international prices. Empirical evidence on LDCs, on the other hand, points out that there exist substantial price distortions. We therefore take into account such distortions and show that these distortions may exert a 
first-order effect on the magnitude of the shadow wage. In addition, we examine the case in which the distortions are being set at socially optimal levels, and analyze their implications for the shadow wage. We also consider the case in which the economy is closed to foreign trade. ${ }^{3}$

(v) Equilibrating mechanisms in the economy. The consequences of new employment creation depend on how the economy arrives at a new equilibrium. ${ }^{4}$ How the economy equilibrates, in turn, depends on which instruments can be potentially controlled by the government, which of these instruments are left unchanged when the new employment is created, and how the government changes the remaining instruments. There are two situations in which the issue of how the economy equilibrates may be ignored: first, if the government does not possess any instrument of control at all and, second, if the government sets every available instrument at its socially optimal level. Given the observed behavior of governments, both of these extremes appear unlikely. We therefore assess the impact of alternative equilibrating mechanisms.

(vi) Distributive judgments. The evaluation of public projects depends both on intertemporal and interpersonal trade-offs (that is, the social valuation of the income of different individuals relative to that of investment). These value judgments are represented in our formulae through clearly identifiable parameters.

\section{The basic model}

Rather than to begin with the general model, we first introduce a strippeddown version, to help focus ideas. Subsequent sections show how this basic model can be both generalized and specialized. In the model of an open economy described below, the government exercises its control on the agricultural sector only indirectly, through (at most) the imposition of commodity taxes and subsidies on peasants' net surplus. ${ }^{5}$ The government proposes to undertake an industrial project which will create new employment. Our objective is to calculate the social cost (the shadow wage) of this employment creation. ${ }^{6}$ We assume at present that there is no endogenous

\footnotetext{
${ }^{3}$ An open and a closed economy are obviously two polar representations. In fact, a variety of trade related rigidities exist in LDCs. In Sah and Stiglitz (1983, 1984b), we discuss some of these rigidities in the context of pricing and taxation.

${ }^{4}$ The term 'equilibrium' does not necessarily imply a conventional Walrasian equilibrium; it also denotes temporary equilibria of the kind that have been recently investigated by Solow and Stiglitz (1968), Bennasy (1975), and Malinvaud (1977), among others.

${ }^{5}$ See Sah and Stiglitz (1984b) for a discussion of the economic reasons behind the restrictions which LDCs may face on the set of tax-price instruments they can employ.

${ }^{6}$ It might be useful here to clarify our usage of the term shadow wage. The shadow wage is a summary statistic which sums up all of the changes in the economy due to the creation of industrial cmployment, multiplied by the social marginal valuation of each of these changes. The shadow wage excludes the value of the direct output contributed by the newly employed
} 
migration between the agricultural and the industrial sectors, the agricultural sector consists of homogeneous family farms, and the industrial wage is rigid. ${ }^{7}$ Other specifications are considered below.

\subsection{Agricultural sector}

The agricultural sector's population is $N^{1}$, and $A$ is total (agricultural) land which is owned equally within the agricultural sector. ${ }^{8} a=A / N^{1}$ is land per worker, and $L^{1}$ is the number of hours worked by each worker. The production technology exhibits constant returns to scale. We can therefore write: $X \equiv X\left(A / N^{1}, L^{1}\right) \equiv X\left(a, L^{1}\right)$ as the output of an agricultural worker. An agricultural worker's consumption of agricultural and industrial goods is denoted by $\left(x^{1}, y^{1}\right)$. The surplus of the agricultural good per agricultural worker is $Q=X-x^{1}$. The relative price of the agricultural good in terms of the industrial good is denoted by $p$. An agricultural worker's budget constraint is

$$
y^{1}=p Q \equiv p\left[X\left(a, L^{1}\right)-x^{1}\right] .
$$

An agricultural worker chooses $x^{1}, y^{1}$, and $L^{1}$, subject to the above budget constraint, to maximize his utility. The resulting level of utility depends on $p$ and $N^{1}$, and it is represented by the indirect utility function: $V^{1} \equiv V^{1}\left(p, N^{1}\right)$. Then

$$
\frac{\partial V^{1}}{\partial p}=\lambda^{1} Q>0 \quad \text { and } \quad \frac{\partial V^{1}}{\partial N^{1}}=-\lambda^{1} p X \varepsilon_{X a} / N^{1}<0
$$

where $\varepsilon_{X a} \equiv \partial \ln X / \partial \ln a$ is the elasticity of the agricultural output per worker with respect to the land per worker, and $\lambda^{i}$ is the (positive) marginal utility of income to a worker in sector $i$.

For later use, define $\varepsilon_{Q p} \equiv \partial \ln Q / \partial \ln p$, and $\varepsilon_{Q_{a}} \equiv \partial \ln Q / \partial \ln a$ as the elasticities of the surplus per agricultural worker with respect to its price, and with respect to the land per agricultural worker. Though the usual restrictions on utility and production functions do not predict the sign of $\varepsilon_{Q p}$, we assume here that $\varepsilon_{Q p}>0$. $\varepsilon_{Q a}$ depends on the scarcity of agricultural land. If land is not scarce, then $\varepsilon_{Q a}=0$, and $\varepsilon_{X a}=0$. For brevity in interpreting our results,

workers. As we shall see later, this statistic is much more general than another summary statistic, opporiunity cost of labor, often employed in the literature, which calculates the net change in the aggregate output due to employment creation.

${ }^{7} \mathrm{~A}$ fixed (real) industrial wage is often justified on the basis of certain unspecified institutional constraints. But, as we shall see, it may be consistent with particular versions of competitive wage determination when wage-productivity effects are taken into account.

${ }^{8}$ Throughout the paper, supcrscripts $i-1$ and 2 denote the agricultural and the industrial sectors respectively. 
we assume throughout that $1>\varepsilon_{Q a} \geqq 0$, that is, land is moderately scarce. The modifications for other values of elasticities are straightforward.

\subsection{Industrial sector}

Industrial population is $N^{2}$. We assume that an industrial worker supplies $L^{2}$ hours of work which are fixed due to technological considerations; a more general case, however, can be easily worked out. An industrial worker's consumption of agricultural and industrial goods is denoted by $\left(x^{2}, y^{2}\right)$, and $w$ is his wage income in terms of the industrial good. The budget constraint of an industrial worker is

$$
p x^{2}+y^{2}=w
$$

An industrial worker chooses $x^{2}$ and $y^{2}$ to maximize his utility. Since $L^{2}$ is fixed, we write the indirect utility as: $V^{2}=V^{2}(p, w)$. Then

$$
\frac{\partial V^{2}}{\partial w}=\lambda^{2}>0 \quad \text { and } \quad \frac{\partial V^{2}}{\partial p}=-\hat{\lambda}^{2} x^{2}<0 .
$$

Define $\varepsilon_{x p}^{2} \equiv-\partial \ln x^{2} / \partial \ln p$, and $\varepsilon_{x w}^{2} \equiv \partial \ln x^{2} / \partial \ln w$ as the elasticities of an industrial worker's consumption of the agricultural good with respect to its price, and with respect to wage income. These elasticities are positive because the consumption goods are assumed to be normal.

The output of an industrial worker is $Y \equiv Y\left(k, L^{2}\right)$, where $k=K / N^{2}$ is the capital stock per industrial worker, and $K$ is the total industrial capital stock. There may be both private and public firms in the industrial scetor, but all firms pay the same wage to their workers and the profits of private firms are entirely taxed away.

\subsection{Market equilibrium}

$N$ is the total population, and

$$
N=N^{1}+N^{2}
$$

The supply of the industrial good is used either for consumption or for investment, $I$. Hence,

$$
I=N^{2} Y+M_{y}-N^{2} y^{2}-N^{1} y^{1},
$$

where $M_{y}$ is the net import of the industrial good. Similarly, the balance 
between the supply and the demand of the agricultural good requires:

$$
N^{1} Q+M_{x}=N^{2} x^{2},
$$

where $M_{x}$ is the net import of the agricultural good. The foreign trade balance is given by

$$
P M_{x}+M_{y}=0,
$$

where $P$ denotes the international relative price of the agricultural good. $P$ is fixed under the small country assumption, but this can be easily relaxed.

For later use, we obtain an alternative expression for investment. Substitution of (1), (3), (7), and (8) in (6) yields:

$$
I=N^{2}(Y-w)+(p-P)\left(N^{2} x^{2}-N^{1} Q\right) .
$$

That is, investment equals the retained part of the industrial output (after deducting industrial wage payment) and the net revenue from trade taxes.

\subsection{Equilibrating mechanism}

Creation of industrial employment changes the sectoral populations which, in turn, alters the demand and supply of various goods. The social impact of employment creation thus depends on the particular equilibrating change which occurs. We assume here that the traded quantities $M_{x}$ and $M_{y}$ change to maintain the equilibrium between the supply and the demand of the agricultural good, (7), and investment changes to maintain the equilibrium in the industrial goods market. That is, the government does not change its tariff policy. Alternative equilibrating mechanisms are examined later.

\section{Determination of the shadow wage}

\subsection{Shadow wage in the basic model}

Define an additive Bergson-Samuelson social welfare function:

$$
J=N^{1} W\left(V^{1}\right)+N^{2} W\left(V^{2}\right),
$$

where $W$ is concave and increasing in $V$. If $\delta$ is the social value of the marginal investment, then the current value of the aggregate social welfare is given by the Hamiltonian:

$$
H=J+\delta I,
$$

in which $I$ is given by (9). 
If the shadow wage is denoted by $s$, then

$$
s=-\frac{1}{\delta} \frac{\mathrm{d} H}{\mathrm{~d} N^{2}}+\frac{\partial\left(N^{2} Y\right)}{\partial N^{2}} .
$$

The industrial good is the numeraire throughout the paper. The first term in (12) is the net social loss from employment creation. ${ }^{9}$ The second term represents the direct contribution of the newly employed worker. This contribution is excluded from the calculation of the shadow wage because the fruits of employment creation should not be counted while computing its cost. $^{10}$

An explicit expression for (12) is derived from (11):

$$
s=w-\frac{1}{\delta}\left[W^{2}-W^{1}\right]-\frac{\beta^{1}}{\delta} p X \varepsilon_{X a}+(P-p) Z,
$$

where

$$
Z=Q\left(1-\varepsilon_{Q a}\right)+x^{2}>0
$$

To obtain the above expressions, we have used (2), (4), and (5), and defined $W^{i}=W\left(V^{i}\right)$, and $\beta^{i} \equiv \lambda^{i} \partial W^{i} / \partial V^{i} . \beta^{i}$ is social value (weight) of a marginal increase in the income of a worker in sector $i$.

Each of the four terms in the expression (13) represents a distinct social effect of moving an agricultural worker to the industrial sector. The first term is the direct cost of the wage payment to the newly employed industrial worker. Naturally, a larger market wage implies a larger shadow wage. The second term captures the change in the welfare of the worker who has moved. The third term represents the effect of reduced congestion on agricultural land. Specifically, a migrant worker releases land área $a$, which adds $p X \varepsilon_{X a}$ to the income of those remaining in the agricultural sector. A higher congestion on agricultural land, therefore, corresponds to a lower shadow wage.

The last term captures what we call the general equilibrium effect of employment creation on the demand and supply of the agricultural good. This can be seen as follows. The agricultural surplus decreases directly by $Q$ because now there is one less agricultural worker. The agricultural surplus increases indirectly, on the other hand, by an amount $Q \varepsilon_{Q a}$ because of the extra land which has now become available to those in the agricultural

\footnotetext{
${ }^{9}$ Our analysis focusses on evaluating projects which are of sufficiently moderate size, so $\delta$ can be taken as fixed.

${ }^{10}$ We exclude only the direct contribution, however. Thus, if industrial employment creation has indirect repercussions on industrial output (for examplc, becausc of a change in workers' efficiency) then the indirect effects are not excluded. Such situations arise later in the paper.
} 
sector. Also, the newly arrived industrial worker consumes $x^{2}$ of the agricultural good. The net shortfall in the supply of the agricultural good is therefore $Z$, as in (14), which is met through increased imports. Employment creation thus increases the net agricultural imports. The gain or loss in the government revenue then is $(P-p) Z$, which is the last term in (13).

Much of the literature on shadow wages has ignored this general equilibrium effect by assuming that there is no price distortion; that is, $p=P$. Empirical studies indicate, however, that not only is this assumption incorrect but, in fact, the price distortions in many developing economies are often large. ${ }^{11}$ Also, if the government were to set the domestic prices at their socially optimal levels then, as we shall see, the optimal prices generally entail price distortions. ${ }^{12}$

A simple example might help in understanding the practical consequences of price distortions. Suppose the domestic price of food is twice (half) the international price, and the workers spend roughly half of their income on food. Then, assuming that investment is highly scarce (that is $\delta$ is very large), that the agricultural land is not scarce, and that the workers' earnings in the two sectors are roughly equal, we find from (13) that the shadow wage is half (twice) the market wage. In contrast, the shadow wage equals the market wage if the general equilibrium effects are ignored. Quite plausible parameters therefore show that the magnitude of the shadow wage will be substantially erroneous if this general equilibrium effect is not taken into account.

\subsection{Special cases}

Many of the results which have been prominent in the literature - and some new results which have not previously been noted - can be obtained as special cases of the expression (13). The specializations entail various specific assumptions concerning the technology and the nature of government policy.

(i) Highly scarce capital. In this case, $\delta$ is very large, and

$$
s=w+(P-p) Z \text {. }
$$

If the capital is highly scarce, then the shadow wage is higher (lower) than the market wage if the domestic price of the agricultural good is lower (higher)

\footnotetext{
${ }^{11}$ See Peterson (1979), and Bale and Lutz (1979), for cxample.

${ }^{12}$ Some models in which there are no restrictions on the government's ability to impose commodity and factors taxes might predict that there should be no distortions. See, for example, Diamond and Mirrlees (1971). This is not the optimal policy, however, in the cases examined later in this paper, or in more general models, for example in Stiglitz and Dasgupta (1971) and in Sah and Stiglitz $(1983,1984 b)$.
} 
than its international price. Obviously, the shadow wage equals the market wage if there are no price distortions.

(ii) No price distortions. A direct implication of (13) is that: In the absence of price distortions, the shadow wage is less than the market wage, so long as industrial workers are better-off than agricultural workers. Other special cases considered below also employ the assumption of no price distortions.

(iii) Utilitarianism. Utilitarianism implies that $W^{i}=V^{i}$, and $\beta^{i}=\lambda^{i}$. Denote the value of the marginal product of an agricultural worker by $g .{ }^{13}$ That is, $g \equiv p X_{L} L^{1}$. Constant returns to scale in agricultural production implies $X=X_{a} a+X_{L} L^{1}$ and, hence, $p X \varepsilon_{X a}=p X-g$. Then, (13) can be written as

$$
s=w-\frac{1}{\delta}\left[V^{2}-V^{1}\right]-\frac{\lambda^{1}}{\delta}(p X-g) .
$$

This corresponds to a result obtained by Little and Mirrlees (1968), Stern (1972), and Newbery (1972).

(iv) Fixed labor hours. If the labor hours supplied by an agricultural worker are fixed and equal to the hours supplied by an industrial worker, then the utility of an agricultural worker can be expressed as a function of his income and the price he faces, that is: $V^{1}=V(p, p X)$ and $V^{2}=V(p, w)$. Moreover, $W$ is concave in a worker's income. ${ }^{14}$ Expression (13) then yields:

$$
s \geqq\left(1-\frac{\beta^{1}}{\delta}\right) w+\frac{\beta^{1}}{\delta} g .
$$

Thus, the shadow wage exceeds a weighted average of the market wage and the marginal product of an agricultural worker.

(v) Output maximizing society. In addition to the assumptions made in (iv) above, if it is assumed that a society maximizes the level of its aggregate output without distinguishing between investment and consumption, or between the consumption of different workers, then $W$ equals a worker's income, and $\delta$ equals one. ${ }^{15}$ Thus, the inequality in (17) is replaced by an equality, and

$$
s=g .
$$

That is, the shadow wage equals the value of the marginal product of an agricultural worker. This was one of the earliest views on the magnitude of

\footnotetext{
${ }^{13}$ The marginal product of an agricultural worker in this paper is the number of hours a worker works times the marginal product of one working hour.

${ }^{14} \mathrm{We}$ assume here that the marginal utility of income is nonincreasing in income.

${ }^{15}$ Under this set of assumptions, the opportunity cost of labor equals the shadow wage.
} 
the shadow wage. This view implied a zero shadow wage, if the marginal product of agricultural labor is zero. ${ }^{16}$

\section{Labor mobility, industrial wage, and industrial productivity}

\subsection{A general model}

Unemployment and endogenous mobility of workers across sectors are common features of many developing economies. We propose here a general model of labor mobility which subsumes many of the existing models. The utility level of an unemployed worker is denoted by $V^{\mathrm{u}}$, and the number of unemployed is denoted by $N^{\mathrm{u}}$. For simplicity, transfer arrangements from the employed to the unemployed workers are ignored here, and it is assumed that the unemployed workers have a fixed level of utility.

The agricultural population is expressed (in a reduced form) as a function of the relative price and the level of industrial employment:

$$
N^{1}=N^{1}\left(p, N^{2}\right) .
$$

(As explained below in footnote 18, the dependence of $N^{1}$ on $w$ is already implicit in the above expression.) Obviously, then, the level of unemployment is also a function of $p$ and $N^{2}$, since

$$
N=N^{1}+N^{2}+N^{\mathbf{u}}
$$

Next, consider the determination of industrial wages. There are several alternative hypotheses concerning how the industrial wage is determined. To obtain an integrated view of the implications of these alternative hypotheses on the shadow wage, we represent the industrial wage schedule through the following reduced form function: ${ }^{17}$

$$
w=w\left(p, N^{2}\right) .
$$

It can be verified that the above reduced form representations of labor mobility and industrial wage determination take into account the relationship between $N^{1}$ and $w \cdot{ }^{18}$ Also, note that $(21)$ is consistent with the view

\footnotetext{
${ }^{16}$ Dixit (1968) studied a model without an agricultural sector, but with a reserve army of unemployed in the industrial sector. Members of this army are subsidized by their working colleagues, such that everyone consumes the same amount, $w N^{2} / N$. The indirect consumption gain to the population from a job creation is $w$. It follows that the corresponding shadow wage is: $s=w(1-\lambda / \delta)$.

${ }^{17}$ Khan (1980) employs a similar representation of industrial wage in the context of a trade model.

${ }^{18}$ Specifically, let $N^{1}$ depend on all of the variables in the economy: that is, $N^{1}=$
} 
that the government cannot perfectly control the level of industrial wage, or with the view that if the government is setting the wage optimally, then the optimal wage may depend on other variables in the economy. ${ }^{19}$

Many recent theories have suggested that the productivity of industrial workers might depend on other variables in the economy, such as the industrial wage and the rate of unemployment. Such a dependence is represented as

$$
Y=Y\left(k, L^{2}, p, N^{2}\right),
$$

where the first two arguments of the function $Y$ continue to represent the direct effect of the capital and labor hours on industrial productivity, while the last two arguments reflect all of the indirect effects. ${ }^{20}$

An advantage of using general functions like (19), (21), and (22) is that the resulting shadow wage formulae are quite free of the precise nature of the institutions in the economy. (The values of parameters in these formulae would, of course, depend on the institutions.) As we shall see below, these functions are easily specialized to represent various specific hypotheses.

For later use, we define the following elasticities. From (22), $\varepsilon_{Y e} \equiv \mathrm{d} \ln Y / \mathrm{d} \ln N^{2}$ is the elasticity of per worker industrial output with respect to industrial employment. Given that the price is fixed in the present model, this elasticity captures all of the indirect effects of the perturbation in the economy on industrial productivity. From (19), $n \equiv-\mathrm{d} N^{1} / \mathrm{d} N^{2}$ is the number of workers who leave the agricultural sector if one industrial job is created. And, from (21), $\varepsilon_{w e} \equiv \mathrm{d} \ln w / \mathrm{d} \ln N^{2}$ is the elasticity of industrial wage with respect to industrial employment. ${ }^{21}$

The relevant Hamiltonian is given by (9) and (11) in which

$$
J=N^{1} W\left(V^{1}\right)+N^{2} W\left(V^{2}\right)+\left(N-N^{1}-N^{2}\right) W\left(V^{\mathbf{u}}\right)
$$

and $N^{1}, w$ and $Y$ are given by (19), (21) and (22), respectively. We derive the

$\bar{N}^{1}\left(p, w, N^{\mathrm{u}}, N^{2}\right)$. Similarly, in general, $w=\bar{w}\left(p, N^{1}, N^{\mathrm{u}}, N^{2}\right)$. These two expressions and (20), then, yield (19) and (21) under the conditions which allow the use of the implicit function theorem. If the economy has a wider set of variables then the above representations can be accordingly expanded. As an example, if there are different prices in the two sectors, then both of these prices will appear as arguments of (19) and (21).

${ }^{19}$ The model of migration proposed in this paper can be further extended to an economy in which there are several regions which differ from one another in resources (e.g. land, population, and skills of workers), in institutions (e.g. how workers' earnings are determined), and in tax regimes (i.e. workers in different regions face different prices).

${ }^{20}$ The dependence of industrial productivity on other variables in the economy is implicit in (22), through an argument similar to that in footnote 18. Also, note that (22) is an aggregation over firms' production functions, each of which can be written (in a symmetric equilibrium) as: $Y^{\mathrm{f}}=Y^{\mathrm{f}}\left(k^{\mathrm{f}}, L^{2}, p, N^{2}\right)$, where the superscript $\mathrm{f}$ denotes a firm, and $k^{\mathrm{f}}$ is a firm's capital per worker. In a more general model, $Y^{f}$ will also be a function of the entire distribution of industrial wages.

${ }^{21}$ We should emphasize that these are total derivatives. 
corresponding shadow wage according to (12). This can be arranged to yield:

$$
s=w-\frac{1}{\delta}\left[W^{2}-W^{\mathrm{u}}\right]+\frac{\phi}{\delta} n+(P-p) Z+\left(1-\frac{\beta^{2}}{\delta}\right) w \varepsilon_{w e}-Y \varepsilon_{Y e},
$$

where

$$
\phi=W^{1}-W^{\mathrm{u}}-\beta^{1} p X \varepsilon_{X a}
$$

and

$$
Z=Q\left(1-\varepsilon_{Q a}\right) n+x^{2}\left(1+\varepsilon_{x w}^{2} \varepsilon_{w e}\right) .
$$

Expression (24) reduces to (13) if $n=1, \varepsilon_{Y e}=0$, and $\varepsilon_{w e}=0$. That is: if the level of unemployment is left unchanged by the creation of industrial cmployment, if the industrial wage is fixed, and if there are no indirect effects on industrial productivity, then the above shadow wage is the same as that derived in the basic model. Thus, the model in section 3 and its specializations can be viewed as special cases of the more general model presented here.

The effect of employment creation on labor mobility and the effect of this on the shadow wage can be decomposed into three parts. First, $n$ migrants from the agricultural sector join the pool of unemployed and $\phi$ is the net loss in the welfare for each worker, after taking into account the gain from reduced congestion on agricultural land [see (25)]. The welfare loss is thus $\phi n / \delta$ in (24). Second, one of the unemployed workers receives the newly created industrial job, and the welfare gain due to this is $(1 / \delta)\left[W^{2}-W^{u}\right]$. Third, labor mobility influences the shortfall $Z$ in the agricultural good. This can be seen in (26), in which $Q\left(1-\varepsilon_{Q a}\right) n$ is the decrease in agricultural supply.

The effect of employment creation on the industrial wage is felt through $\varepsilon_{w e}$. If, for example, the industrial wage increases with industrial employment, then the new project will increase the wage payment to the inframarginal industrial workers. This, in turn, makes them better off, but at the expense of public revenue. The net of these two effects is represented in the fifth term in (24). The induced change in the industrial wage also affects the net shortfall in agricultural good, as can be seen in the expression (26). Finally, the loss or gain due to the indirect effects on industrial productivity is represented by the last term in the right-hand side of (24).

\subsection{Harris-Todaro migration hypothesis}

A special case of the above general model of labor mobility is the HarrisTodaro hypothesis [Harris and Todaro (1970)], according to which a migrant from the agricultural sector finds an industrial job with probability $N^{2} /\left(N-N^{1}\right)$, and becomes unemployed otherwise. Migration continues until 
the expected utility level of a potential migrant equals the utility level of an agricultural worker. This hypothesis is therefore a special case of (19) in which

$$
N V^{1}=N^{1} V^{1}+N^{2} V^{2}+\left(N-N^{1}-N^{2}\right) V^{u}
$$

where, it will be recalled, $V^{1}$ is a function of $p$ and $N^{1}$, and $V^{2}$ is a function of $p$ and $w$. For simplicity, we assume here that the social welfare function is utilitarian, that is, $W(V)=V$ and $\beta^{i}=\lambda^{i}$. While a more general approach is easily possible, as we shall see below, this assumption enables us to ignore here the issue of defining the social welfare over the ex ante versus the ex post utilities of workers. Also, to keep $N^{\mathrm{u}}$ positive, we assume that $V^{2}>V^{1}>V^{u}$. The above model is not meaningful otherwise.

Perturbing (27), we obtain:

$$
n=\frac{N^{1}\left(V^{2}-V^{\mathrm{u}}+\lambda^{2} w \varepsilon_{w e}\right)}{N^{1}\left(V^{1}-V^{u}\right)+\left(N-N^{1}\right) \lambda^{1} p X \varepsilon_{X a}} .
$$

Substitution of the above in (24) yields:

$$
s=w\left(1+\varepsilon_{w e}\right)-\frac{N \hat{\lambda}^{1}}{N^{1} \delta} p X \varepsilon_{X a} n+(P-p) Z-Y \varepsilon_{Y e},
$$

where $Z$ is given by (26).

On comparing (29) with the carlicr cxpressions for the shadow wagc, (13) and (24), it is clear that the shadow wage now does not depend on the differences in the utilities of different workers. This is what we would expect since all workers have the same expected utility in the present model. ${ }^{22}$

\section{Special cases}

(i) Consider the special case in which there is no congestion on agricultural land, there are no induced effects of employment creation on industrial wage and productivity, and the domestic price equals the international price. Then, from (29), the shadow wage equals the market wage, regardless of the society's valuation of investment versus consumption. This well-known result $^{23}$ reversed the presumption of the earlier literature that the shadow

\footnotetext{
${ }^{22}$ The expressions for the shadow wage based on the Harris-Todaro hypothesis, such as (29) and those to be derived later, are more general than they appear. This is because the only property of the migration hypothesis which has been actually used here is that the social welfare can be represented by $N V^{1}$. The resulting expressions for the shadow wage therefore hold under any migration mechanism, provided the society focusses its attention only on the welfare of agricultural workers.

${ }^{23}$ See Stiglitz (1971, 1974), Harberger (1971) and Heady (1981), among others.
} 
wage is smaller than the market wage, that its value is critically dependent on the society's intertemporal valuation, and that it approaches the market wage only when the social value of investment (relative to consumption) is very high.

The basic reason for this result is that the migration in the present special case does not change the aggregate level of utility or consumption in the economy and, hence, the only effect of employment creation is on investment. The utility level of an agricultural worker is fixed, since $\varepsilon_{X a}=0$, and the utility level of an industrial worker is fixed, since there is no effect of migration on the aggregate expected utility. Since the only effect of creating an industrial job is on investment [which, from (9), is reduced by the market wage], it follows that the shadow wage equals the market wage. ${ }^{24}$

(ii) Consider an output maximizing society with land congestion, in which there are no price distortions, and there are no induced cffects on industrial wage and productivity. Recall that the output mazimization implies $\lambda^{1}=\delta=1, V^{1}=p X$, and $V^{2}=w$. Substitution of these in (28) and (29) yields:

$$
s=w N^{1}\left(1-\varepsilon_{X a}\right) /\left[N \varepsilon_{X a}+N^{1}\left(1-\varepsilon_{X a}\right)\right] .
$$

Thus, $s<w$, since $\varepsilon_{X a}<1$ from the standard properties of production function. This result shows, in a simple setting, that the effect of land congestion is to reduce the shadow wage. ${ }^{25}$

\section{Industrial wage determination}

Many recent studies have postulated that the net output (net of hiring and training costs, for example) of an industrial firm may be a function of, among other things, the wage this firm pays, the wages other firms pay, and the level of industrial unemployment; and that these effects, in turn, influence the wages that are paid to workers. ${ }^{26}$ In this section we show how these wage determination mechanisms can be treated as special cases of the model presented earlier. We also show that our model can be employed to study

\footnotetext{
${ }^{24}$ This result can be looked at in an alternative way in an output maximizing society (see the special case (v) in section 3.2) in which the earnings (consumption) of a worker in both sectors are fixed and, therefore, a change in the investment is the same as a change in the output. The impact on the aggregate output of creating an industrial job in this economy is the output of one agricultural worker times the number of such workers who migrate. Under the HarrisTodaro hypothesis, this product is just equal to the industrial wage. To see this in the simplest case in which everyone is risk-ncutral, note that: $V^{1}-p X, V^{2}=w$, and $V^{u}=0$. (28) then yiclds: $n=w / p X$. The loss in output is thus: $n p X=w$. For a discussion of this simple case, see Stiglitz $(1971,1974)$. Our analysis in this paper is, of course, much more general and does not depend on these restrictive assumptions.

${ }^{25}$ See Stiglitz (1982a) for a parallel result.

${ }^{26}$ See Stiglitz $(1971,1974,1982 a, 1982 b)$, and the references therein.
} 
wage determination in many more institutional settings than those considered in the existing literature.

Most of the general points can be established in the context of the wageproductivity hypothesis. This hypothesis suggests that the efficiency per work hour, $b$, depends on the wage; ${ }^{27}$ that is, $b=b(w)$, where $b_{w} \geq 0$ is the relevant range, and $Y=Y\left(k, b L^{2}\right)$. The institutional setting which has been emphasized in the literature is the one in which private industrial firms minimize the labor cost per efficiency unit, $w / b(w) L^{2}$, and the resulting wage is characterized by

$$
b_{w}=b / w
$$

Thus: The level of the efficiency wage paid by firms is a fixed technological parameter. The substitution of $\varepsilon_{w e}=0$ and $\varepsilon_{Y e}=0$ in (24) yields the corresponding shadow wage.

Now consider an alternative institutional setting in which the industrial firms are publicly owned (that is, the level of industrial employment is publicly determined) and the government instructs firms to maximize their profits (this directive may not always be socially optimal, as we shall soon see). The firms then maximize $(Y-w)$, and the industrial wage is characterized by

$$
b_{w}=1 / L^{2} Y_{L}
$$

where $Y_{L} \equiv \partial Y / \partial\left(b L^{2}\right)$. Clearly, in this case the industrial wage depends on the level of industrial employment. The induced effect on productivity is represented by $\varepsilon_{Y e}=\varepsilon_{Y L} \varepsilon_{b w} \varepsilon_{w e}$, where $\varepsilon_{Y L}=\partial \ln Y / \partial \ln \left(b L^{2}\right)$, and $\varepsilon_{b w}=\partial \ln b / \partial \ln w$. Substitution of these in (24) yields the corresponding shadow wage.

If, on the other hand, the government sets the optimal wage taking into account the wage-efficiency effects, then, using the relevant Hamiltonian, it can be verified that the optimal wage depends on the variables in both sectors of the economy and that, in general, the resulting wage schedule does not entail an equalization of the social weight on investment, $\delta$, and the social weight on the income of an industrial worker $\beta^{2} .^{28}$

For illustration, consider the simple case in which there is no price distortion, and there is no endogenous migration. The socially optimal industrial wage is then obtained from (9), (10) and (11) as

$$
\beta^{2} / \delta=1-Y_{L} L^{2} b_{w}
$$

\footnotetext{
${ }^{27}$ More correctly, the productivity also depends on prices [see Sah and Stiglitz (1984b)]. This dependence is suppressed here because prices are fixed in the present model.

${ }^{28}$ This should be contrasted with standard models in which the social weights on public revenue and on the income of a person arc equal if the income of this person can be controlled by the government.
} 
Clearly, $\beta^{2}$ does not always equal $\delta$ because of the wage efficiency effects. Now consider two further special cases in which the social weights are exogenously specified. First, if $\delta$ is very large relative to $\beta^{2}$, then (32) and (33) are the same. This should not be surprising, since if the society maximizes investment, then the optimal wage paid by the government is the same as what it would be if public sector managers are instructed to maximize their profit. Second, if $\beta^{2}=\delta$, then (33) yields $b_{w}=0$. Thus, in an output maximizing society, the optimal industrial wage is sufficiently high, so that the effects of wage on productivity no longer exist. It follows in the present case, then, that the optimal industrial wage is higher in an output maximizing society than what it is in an investment maximizing society, or in an economy in which private firms minimize the cost of labor in efficiency units.

For other hypotheses concerning industrial wage determination, the relevant issues are quite similar to those already discussed above. For instance, the wage-quality hypothesis posits that the wage paid by a firm (relative to other firms and relative to the agricultural sector) induces a sorting of workcrs according to their quality. If the private firms minimize their unit cost of labor in efficiency units, then in a symmetric equilibrium, the wage is given by (31), where $b=b\left(w, N^{2}\right) \cdot{ }^{29}$ Clearly, therefore, employment creation has an induced wage effect as well as an indirect effect on productivity.

Similarly, according to the labor-turnover hypothesis, the training cost to a firm (which reduces its net output) depends on the quit rate of workers. If private firms minimize their total labor cost then, in a symmetric equilibrium, it turns out that the industrial wage depends on urban unemployment rate and on the number of workers in the agricultural sector. It is clear therefore, that this case as well as those arising in alternative institutional settings, can be treated as special cases of the model developed in section 4.1.

We have thus identified the properties of the industrial sector which are critical in the determination of the shadow wage, and have shown how the relevant reduced form expressions depicting the industrial wage schedule and the migration mechanism can be specialized to a variety of technological, behavioral, and institutional hypotheses. The same reduced form expressions (and therefore the same formulae for the shadow wage) are consistent with quite different technological and behavioral assumptions; while the same technological assumptions, in conjunction with different behavioral postulates, yield markedly different shadow wages.

\section{Structure of the agricultural sector}

Our earlier specification that the agricultural sector consists of homo-

${ }^{29}$ See Stiglitz (1982b). The wage-quality hypothesis has some additional complexities. For example, if earnings vary across agricultural workers of different abilities, then the effect of a public project on the quality of agricultural workers also nceds to be taken into account in calculating the shadow wage. 
geneous family farms is restrictive. A full investigation of the impact that alternative institutional structures within the agricultural sector have on the shadow wage requires a more detailed model containing, among other things, different classes of individuals (landowners, sharecroppers and landless workers, for example), the migration behavior of these classes, the reallocation of land entailed by migration, the mechanisms which determine agricultural wages and earnings, and the tax instruments which the government employs in the agricultural sector. A perturbation of such a model due to industrial employment creation would thus affect not only the distribution of welfare within the agricultural sector, but also the agricultural surplus and the level of public investment.

For instance, if agricultural wages increase due to a reduction in the agricultural population, then, as we pointed out above, the net sellers of labor gain, whereas the net buyers of labor lose. If the economy is closed to international trade (discussed below in section 8), then a project has general equilibrium price effects; if the prices of agricultural goods increase, then the net sellers of these goods gain whereas the net buyers lose. Also, migration may affect the distribution of rents and profits associated with land ownership, particularly if the new project induces some of the landowners to migrate to the urban sector. The precise consequences of this would depend, of course, on the institutional arrangements; in some economies, migrants do not lose their right to receive 'rents' from their land, while in others they do. In addition, there may be induced effects on individuals' incentives (and hence on their surplus and welfare) which are determined, in part, by the rules for sharing output and work within families and between landowners and sharecroppers. ${ }^{30}$

In the remainder of this section we focus on the distributional consequences of changes in agricultural wages and profits. Specifically, we reconsider the basic model (section 2) with the following modifications concerning the agricultural sector.

(i) Heterogcnous farmers. Consider an agricultural sector consisting of a spectrum of landowning classes as well as landless workers, who buy and sell their labor services. $N^{1 h}$ denotes the agricultural population in group $h$. An individual in group $h$ has land area $A^{h}$, and his net labor supply (that is, labor hours supplied minus the labor hours employed on his farm) is $L^{1 h}$. The landless workers are denoted by $h=1$. Clearly, $A^{1}=0$, and $L^{11}>0$. The newly created industrial job is awarded to one of the landless workers, and the populations of various landowning groups remain unchanged. The

\footnotetext{
${ }^{30}$ For instance, if the output is equally shared among family members, then there is an attenuation of incentives due to the difference between the average product and the marginal product, and this attenuation will be affected if some of the family members migrate to cities. Note, however, that there is something slightly peculiar about such models which assume that social customs dictate an equal sharing of output within a family, but that social customs cannot, or do not, support efficient 'work-sharing'.
} 
schedule of the rural wage rate (per hour) is represented as $w^{1}=w^{1}\left(p, N^{11}\right)$. Its elasticity with respect to the population of landless workers is denoted as $\varepsilon_{w e}^{1} \equiv-\mathrm{d} \ln w^{1} / \mathrm{d} \ln N^{11} . N^{1} Q$ continues to denote the total agricultural surplus, where $N^{1}=\sum_{h} N^{1 h}$ is the total agricultural population, and $Q$ is the average agricultural surplus per member of the agricultural population.

The first term in the right-hand side of the social welfare function (10) now becomes: $\sum_{h} N^{1 h} W\left(V^{1 h}\left(p, w^{1}\right)\right)$, and the corresponding shadow wage is given by

$$
s=w-\frac{1}{\delta}\left[W^{2}-W^{11}\right]+(P-p) Z+c .
$$

where

$$
c=-\frac{1}{\delta} w^{1} \varepsilon_{w e}^{1} \sum_{h} \beta^{1 h} \mu^{1 h} L^{1 h}
$$

and $\mu^{1 h}=N^{1 h} / N^{11}$.

The new term, $c$, in (34) and (35), represents the induced effects of industrial employment creation on the distribution of welfare in the agricultural sector. We assume here that the agricultural wage rate increases if there are fewer landless workers, that is, $\varepsilon_{w e}^{1}>0$. (As we shall see below, this assumption is justified under certain plausible conditions.) Then, (34) and (35) show that the induced gains to the net suppliers of labor reduce the shadow wage, whereas the induced losses to the net buyers of labor increase the shadow wage. This is what we would have expected based on our earlier discussion.

Although the above derivation of the shadow wage is consistent with a variety of mechanisms for agricultural wage determination, we focus on the case where the wage is determined from a clearing of agricultural labor market, that is, from

$$
\sum_{h} N^{1 h} L^{1 h}\left(p, w^{1}\right)=0 .
$$

If household $h$ supplies $L^{\text {sh }}$ hours of labor, and $L^{\mathrm{d}}$ hours of labor are used on a unit land, then $L^{1 h}=L^{\text {sh }}-A^{h} L^{\mathrm{d}}$. Denote $\varepsilon_{L w}^{\mathrm{sh}} \equiv \partial \ln L^{\mathrm{sh}} / \partial \ln w^{1}$ as the elasticity of labor supply for household $h$, and $\varepsilon_{L w}^{\mathrm{d}} \equiv-\partial \ln L^{\mathrm{d}} / \partial \ln w^{1}$ as the elasticity of labor demand on a unit land. Then a perturbation of (36) with respect to $w^{1}$ and $N^{11}$ yields:

$$
\varepsilon_{w e}^{1}=L^{11} / \sum_{h} \mu^{1 h}\left(L^{s h} \varepsilon_{L w}^{s h}+A^{h} L^{\mathrm{d}} \varepsilon_{L w}^{\mathrm{d}}\right) .
$$


It follows that a sufficient set of assumptions for (37) to be positive is that the individuals' labor supplies are nondecreasing in the wage rate, and that the farm use of labor is decreasing in wage rate. ${ }^{31}$ But even if the labor supply curve is backward bending, (37) will still be positive, provided increases in wage do not induce too large a reduction in labor supply. This assumption seems plausible, and we make it in the rest of this section.

A special case worth noting here is that of an agricultural sector consisting of two classes: landless workers and landlords (denoted by $h=2$ ). Then from (36), $L^{11}=-\mu^{12} L^{12}$. Substituting this in (35), we obtain:

$$
c=\frac{1}{\delta}\left(\beta^{12}-\beta^{11}\right) w^{1} L^{11} \varepsilon_{w e}^{1}
$$

This expression is quite intuitive since in the two-class case the induced wage gain to the landless is exactly equal to the loss to the landlords. If the society is averse to inequality (that is, $\beta$ is decreasing in income), ${ }^{32}$ then a net social gain arises from this induced transfer from the poor to the rich. From (34) and (38), therefore, the resulting social gain reduces the shadow wage.

(ii) Land rents. If the government captures some of the profits (rents) in the agricultural sector, then the public revenue (and, hence, the shadow wage) will be influenced by migration. For brevity, we consider here a polar case in which the agricultural sector is organized through government-owned parastatals, or through privately owned parastatals whose profits are entirely taxed away. $N^{1}$ denotes the population of homogeneous agricultural workers, each of whom works for $L^{1}$ hours and receives a wage rate $w^{1}$ per hour. The profit in agriculture is $N^{1}\left(p X-w^{1} L^{1}\right)$, and this profit is now added to the investment expression (9). The resulting shadow wage is given by (34), where now

$$
c=\left(1-\frac{\beta^{1}}{\delta}\right) w^{1} L^{1} \varepsilon_{w a}^{1}+\left(1-\varepsilon_{I, w}^{1} \varepsilon_{w a}^{1}\right)\left(p X_{L}-w^{1}\right) L^{1},
$$

where $\varepsilon_{L w}^{1} \equiv \partial \ln L^{1} / \partial \ln w^{1}$ is the labor supply elasticity of an agricultural worker. ${ }^{33}$

The first term on the right-hand side of (39) represents the induced wage effect which we had investigated above. In fact, this term is quite similar to the corresponding expression (38) in a two-class agriculture. This should not be surprising since, in the present model, the government acts as the

\footnotetext{
${ }^{31}$ If individuals' labor supplies are fixed and equal, then $L^{\text {sh }}=L^{11}$, and $\varepsilon_{L w}^{\text {sh }}=0$. Substitution of these and (36) in (37) yields: $\varepsilon_{w e}^{1}=N^{11} / N^{1} \varepsilon_{L w}^{\mathrm{d}}$. As is obvious, this elasticity does not depend on the land distribution within the agricultural sector.

${ }^{32} \partial \beta / \partial V<0$, if $W$ is strictly concave and if the assumption in footnote 14 holds.

${ }^{33}$ Note that in (34), $W^{11}$ is now $W^{1}$, and, in (39), $\varepsilon_{w e}^{1}=-\mathrm{d} \ln w^{1} / \mathrm{d} \ln N^{1}$.
} 
'landlord'. ${ }^{34}\left(p X_{L}-w^{1}\right)$ is the marginal profit (which could be positive, zero or negative) from an hour of labor. The second term on the right-hand side of (39), therefore, represents the loss of profit due to the migration of one agricultural worker, and due to effect that this migration may have on the labor hours supplied by those who remain in the agricultural sector. Next, the labor market clearing condition (36) now becomes: $N^{1} L^{1}=A L^{\mathrm{d}}$. This yields: $\varepsilon_{w e}^{1}=1 /\left(\varepsilon_{L w}^{1}+\varepsilon_{L w}^{\mathrm{d}}\right)>0$, and $\left(1-\varepsilon_{L w}^{1} \varepsilon_{w e}^{1}\right)=\varepsilon_{L w}^{\mathrm{d}} /\left(\varepsilon_{L w}^{1}+\varepsilon_{L w}^{\mathrm{d}}\right)>0 .{ }^{35}$ From (34) and (39), therefore, we obtain the following result.

If there are no price distortions, if investment is highly scarce, and if agricultural workers are paid no more than their marginal product, then the shadow wage is higher than the market wage. The reasoning is simple. The migration of an agricultural worker, in the present case, implies that the government not only pays a higher wage to those who remain in the agricultural sector, but it also loses some profit because the total number of agricultural labor hours have decreased due to migration. ${ }^{36}$ The conventional belief that the shadow wage equals the market wage when there is no distortion and when investment is scarce, therefore, is incorrect in the present case.

\section{Shadow wage with optimal prices}

Throughout our analysis we have stressed the importance of the deviation between the domestic and the international prices in the determination of the shadow wage. Our results are valid regardless of how the domestic prices are determined, so long as they do not change as the industrial employment is created. We now examine how the domestic prices would be set if they were being determined optimally, and what the optimal prices, in turn, imply for the shadow wage.

For brevity, consider the basic model of the agricultural sector (section 2), ignore the induced effects on industrial productivity, and assume utilitarianism and the Harris-Todaro hypothesis. (A more general analysis is easily possible.) The industrial wage is given by (21). Differentiation of the relevant Hamiltonian, given by (9), (11) and (23), with respect to $p$, characterizes the optimal rate of subsidy on the agricultural surplus as

$$
\frac{p-P}{p}=\frac{\frac{\lambda^{1}}{\delta} N\left(Q-X \varepsilon_{X a} m_{p}\right)-\frac{N^{2} w}{p} \varepsilon_{w p}+M_{x}}{N^{1} Q \bar{\varepsilon}_{Q p}+N^{2} x^{2} \bar{\varepsilon}_{x p}^{2}} .
$$

${ }^{34}$ Unlike (38), however, the first term on the right-hand side of (39) is positive if $\delta>\beta^{1}$, that is, if investment is socially more valuable than an agricultural worker's income.

${ }^{35}$ It should be obvious that these signs are valid even if the labor supply is decreasing in the wage rate, provided $\varepsilon_{L_{w}}^{1}+\varepsilon_{L_{w}}^{\mathrm{d}}>0$.

${ }^{36}$ In fact, our result holds even if the government keeps the wage unchanged, provided agricultural workers arc paid less than their marginal product. This can be seen directly from (34) and (39), by substituting $\varepsilon_{w a}^{1}=0$. 
In the above expression we have defined the following elasticities. From (19), $m_{p} \equiv \mathrm{d} \ln N^{1} / \mathrm{d} \ln p$ is the elasticity of the agricultural population with respect to the relative price and, from (21), $\varepsilon_{w p} \equiv \mathrm{d} \ln w / \mathrm{d} \ln p$ is the elasticity of industrial wage with respect to price. $\bar{\varepsilon}_{Q p} \equiv \mathrm{d} \ln \left(N^{1} Q\right) / \mathrm{d} \ln p=\varepsilon_{Q p}+$ $\left(1-\varepsilon_{Q a}\right) m_{p}$ is the elasticity of total agricultural surplus with respect to its price, and $\bar{\varepsilon}_{x p}^{2} \equiv-\mathrm{d} \ln x^{2} / \mathrm{d} \ln p=\varepsilon_{x p}^{2}-\varepsilon_{x w}^{2} \varepsilon_{w p}$ is the own price elasticity of the consumption of agricultural good by an industrial worker, taking into account the induced effect of price on wage. It can be verified from (27) that $m_{p}>0$, and thus $\bar{\varepsilon}_{Q p}>0$.

Expression (40) may be substituted back into (29) to obtain an expression for the shadow wage, expressed in terms of the underlying reduced form general equilibrium parameters of the economy. Specialization of this general formula is a straightforward matter. Here we show that, under certain circumstances, whether the domestic price is higher or lower than the international price depends solely on the direction of trade flows.

Specifically, if the induced effects on industrial wage and on agricultural land congestion are not significant, that is, $\varepsilon_{X a}$ and $\varepsilon_{w p}$ are negligible, then (40) yields: $p>P$, if $M_{x} \geqq 0$. Also, $p<P$ if $M_{x}<0$, and if $\delta$ is very large. That is: The optimal domestic price of the agricultural good is higher than its international price if the country imports this good. The reverse is true if the country exports the agricultural good, and if investment is highly scarce.

Combining the above results with (29), we find that, if the domestic price is being set optimally, then: The shadow wage is smaller than the market wage if the country imports the agricultural good. The reverse is true if the country exports the agricultural good and if investment is highly scarce.

Special case. Among the very few studies on the shadow wage which do not assume undistorted trade are those by Dixit and Stern. ${ }^{37}$ They consider a model in which the society maximizes investment, there is no endogenous migration, the industrial wage equals agricultural income, and the agricultural output does not depend on its price; that is: $\delta, \infty, n=1, m_{p}=0$, $w=p X$, and $X=X\left(N^{1}\right)$. These assumptions also imply: $\varepsilon_{w p}=1$, and $\bar{\varepsilon}_{x p}^{2}=$ $\left(X-x^{2}\right) \varepsilon_{Q p} / x^{2}$. Substitution of these in (40) yields the result:

$$
\frac{P-p}{p}=\frac{1}{\varepsilon_{Q p}}
$$

\section{Alternative equilibrating mechanisms}

There are two main points concerning how the shadow wage is affected by the mechanism which brings the economy back into a (new) equilibrium after

\footnotetext{
${ }^{37}$ Dixit (1971) and Dixit and Stern (1974). A related paper is by Newbery (1974).
} 
a project is undertaken. First, alternative equilibrating mechanisms, in general, entail different social costs ${ }^{38}$ and, hence, imply different shadow wages. Second, if all of the available policy instruments are set at their socially optimal levels, then alternative equilibrating mechanisms imply the same shadow wage. Though both of these points hold in more general models, we examine them here in the context of the simple model outlined in section 2.

We have assumed so far that the traded quantities change in response to the creation of industrial employment, while the domestic prices remain unchanged. Now consider an alternative mechanism in which a change in domestic prices equilibrates the economy, while the traded quantities remain unchanged. ${ }^{39}$ A closed economy is clearly a special case of the present formulation, since the traded quantities are always zero in such an economy.

Using (7), the expression for investment, (9) can be restated as

$$
I=N^{2}(Y-w)+(p-P) M_{x}
$$

in which $M_{x}$ is assumed to be fixed. In addition, eq. (7) now represents an explicit constraint on the economy. The industrial employment creation, therefore, must be accompanied by a price change so that this constraint remains satisfied. Expression (42) along with (10), defines the Hamiltonian (11), and

$$
s=-\frac{1}{\delta}\left[\frac{\partial H}{\partial N^{2}}+\frac{\partial H}{\partial p} \frac{\mathrm{d} p}{\mathrm{~d} N^{2}}\right]+\frac{\partial\left(N^{2} Y\right)}{\partial N^{2}} .
$$

The middle term in the above expression is new, in comparison to (12). This term represents the indirect loss in social welfare duc to the change in price which keeps (7) in balance.

A perturbation of (7) yields:

$$
\frac{\mathrm{d} p}{\mathrm{~d} N^{2}}=\frac{p Z}{N^{1} Q \varepsilon_{Q p}+N^{2} x^{2} \varepsilon_{x p}^{2}},
$$

where recall that $Z$ is the shortfall between the demand and supply of the agricultural good, induced by the industrial job creation. $Z$ is given by (14), and it is positive. Therefore: The creation of industrial employment is

\footnotetext{
${ }^{38}$ Blitzer, Dasgupta and Stiglitz (1981) consider this issue in the context of the shadow foreign exchange rate determination.

${ }^{39}$ Of course, the government can employ a combination of equilibrating mechanisms. The resulting shadow wage for any such combination can be studied by examining the effects of each distinct mechanism. Note, however, that the equilibrating mechanism is not always a matter of choice for the government. For example, if there are restrictions on the quantities that a country can export or import, then the relevant shadow wage is the one which is derived in this section.
} 
accompanied by an increase in the price of the agricultural good, if a change in the domestic prices is the equilibrating mechanism.

Using (43) and (44), we obtain the following expression for the shadow wage:

$$
s=w-\frac{1}{\delta}\left[W^{2}-W^{1}\right]-\frac{\beta^{1}}{\delta} p X \varepsilon_{X a}+t Z,
$$

where

$$
t=\frac{p}{\delta}\left[\frac{N^{2} \beta^{2} x^{2}-N^{1} \beta^{1} Q-\delta M_{x}}{N^{1} Q \varepsilon_{Q p}+N^{2} x^{2} \varepsilon_{x p}^{2}}\right] .
$$

Now contrast (13) and (45). The two expressions for the shadow wage are based on the same underlying model, but they differ in their equilibrating mechanisms. Not surprisingly, therefore, the only difference between expressions (13) and (45) is in their last term which, as we saw above, represents the social cost of meeting the shortfall, $Z$.

Specifically, in (13) the shortfall is removed through an increase in the net agricultural import and, as one would expect, the social cost of meeting a unit of shortfall $(P-p)$. In the present case, an increase in the price of the agricultural good removes the shortfall, and the social cost of meeting a unit of shortfall is $t$, given by expression (46). To understand this expression, note that a price increase hurts industrial workers, helps agricultural workers, and increases (decreases) the public revenue if the net agricultural import is positive (negative). Each of these three effects have societal consequences which are seen clearly in the numerator of the square brackets in (46).

Next consider the case in which the government sets the available policy instruments at their optimal levels. It is intuitive that in this case the social cost of alternative adjustment policies will be equalized and, thus, the shadow wage would be the same under alternative equilibrating mechanisms. This intuition can be verified as follows. If we derive the optimal price in the present model, following the approach of section 7 , then we find that the optimal price is characterized by

$$
P-p=t
$$

where $t$ is given by (46). Thus, the social costs of meeting the shortfall, and the shadow wage, are the same under the two equilibrating mechanisms we have considered.

We now examine two special cases of (45).

\footnotetext{
${ }^{40}$ It should be obvious that the expression (45) holds for other equilibrating mechanisms as well. The only parameter which needs to be recalculated is $t$.
} 
(i) Highly scarce investment. In this case, (45) and (46) yield:

$$
s=w-\frac{p Z M_{x}}{N^{1} Q \varepsilon_{Q p}+N^{2} x^{2} \varepsilon_{x p}^{2}} .
$$

Thus, whether the shadow wage is higher or lower than the market wage depends simply on whether the country exports or imports the agricultural good. This is because the only relevant gain or loss from the equilibrating price increase in this case is due to the change in investment, given by (42). If $M_{x}$ is positive, then the society gains, and the shadow wage is lower than the market wage, and the reverse happens if $M_{x}$ is negative.

(ii) Closed economy. If the economy is closed to international trade, or if it is nearly self-sufficient, then $M_{x}=0$. From (46), therefore, $t=p\left(\beta^{2}-\beta^{1}\right) / \delta\left(\varepsilon_{Q p}+\right.$ $\left.\varepsilon_{x p}^{2}\right)$, which is negative if the agricultural workers are worse off than the industrial workers. ${ }^{41}$ Substituting this in (45), we obtain the following result: In a closed economy, if the agricultural workers are worse off than the industrial workers, then the shadow wage is smaller than the market wage.

The intuition behind this result is quite clear. If agricultural workers are worse off, then industrial employment creation yields a direct welfare gain to those who receive the newly created jobs, and it yields an indirect welfare gain to those who remain in the agricultural sector due to an increase in the price of agricultural good, and due to the reduced congestion. These two effects lead to a reduction in the shadow wage.

A further special case of a closed economy is one in which investment is highly scarce. In this case, (48) yields $s=w$. That is, the shadow wage equals the market wage. This has an interesting implication. The conventional belief that the shadow wage equals the market wage can be interpreted as a limiting casc (of highly scarce investment) in an open cconomy without trade distortions, as well as in a closed economy.

\section{Remarks}

(i) When individuals' migration decisions are based on expected utilities, then the shadow wage may be affected by whether the social welfare is calculated on the basis of the ex ante or the ex post utilities of individuals. ${ }^{42}$ Consider the simple example of the Harris-Todaro hypothesis with no land congestion, and no induced effect on the industrial wage. Expression (23) is the social welfare of individuals based on their ex post utilities. Expressions (23) and (28) yield: $\mathrm{d} J / \mathrm{d} N^{2}=\left(W^{2}-W^{u}\right)-\left\{\left(W^{1}-W^{u}\right)\left(V^{2}-V^{u}\right) /\left(V^{1}-V^{u}\right)\right\}$. Since, $V^{2}>V^{1}$, the last expression is negative (zero) if $W$ is strictly concave

\footnotetext{
${ }^{41}$ See footnote 32.

${ }^{42}$ See Heady (1981) on this distinction.
} 
(linear) in $V$. The social welfare of individuals based on their ex ante utilities, on the other hand, is $J=N W\left(V^{1}\right)$, and thus $\mathrm{d} J / \mathrm{d} N^{2}=0$. Using these derivations it can be verified that if the society is averse to inequality, then the shadow wage corresponding to a social welfare function based on ex post utilities is higher than that corresponding to a social welfare function based on ex ante utilities; and that the two shadow wages are equal if the society is utilitarian. ${ }^{43}$ The reason is simple. In the present case, all individuals have the same ex ante utilities, but the pool of unemployed becomes larger when new industrial jobs are created. There is an added social cost, therefore, if the individuals' ex post utilities matter to the society.

(ii) We have emphasized above that the shadow wage depends on the equilibrating mechanisms within the economy. There are some other possibilities which might be important in this context. First, it is possible in some cases that a government manages its policy instruments in a manner such that some markets do not clear. As an extreme example, if a government creates industrial employment without allowing other variables (such as prices or traded quantities) to change, then a shortage of food might emerge in cities. The government may then attempt to remove this shortage through nonprice methods such as rationing and queues. The derivation of the shadow wage in such cases will have to take into account the nonprice methods which are employed to arrive at the final quantity balances. ${ }^{\mathbf{4 4}}$

Second, the economy may be in a temporary equilibrium such that some of the prices are rigid and some of the markets, other than that for labor, are characterized by excess supply or demand. In such cases, it is necessary to base the shadow wage derivation on an explicit model of the short term equilibrium. $^{45}$

(iii) The models we have analyzed can be easily enlarged to accommodate a multiplicity of goods, and to include additional instruments of policy. For example, if the government can maintain different relative prices in the agricultural and the industrial sectors, denoted by $p$ and $q$ respectively, then it can be shown that the shadow wage in the basic model is given by (13), provided we replace the last term in the right-hand side of (13) by

$$
(P-p)\left(Q-a \frac{\mathrm{d} Q}{\mathrm{~d} a}\right)-(P-q) x^{2}
$$

The intuition is obvious. The government's gain or loss due to the general equilibrium effects on the demand and supply of the agricultural good is now

\footnotetext{
${ }^{43}$ To see this, substitute (11) into (12), and note that only $\mathrm{d} J / \mathrm{d} N^{2}$ differs for the two alternative specifications under consideration.

${ }^{44}$ See Sah (1982) on the welfare implications of alternative nonprice instruments.

${ }^{45}$ See Roberts (1982) and Marchand, Mintz and Pesticau (1983), for example, on the shadow pricing in the context of a single sector economy in temporary equilibrium.
} 
valued differently in the two sectors. Moreover, (49) readily generalizes to the case of many goods if the prices and quantities are interpreted as vectors. We have developed such disaggregated models elsewhere [Sah and Stiglitz (1983, 1984b)] to study the design of taxation and pricing in LDCs.

\section{Conclusion}

While the importance of using shadow prices and wages in the evaluation of public expenditure and projects has been widely recognized in LDCs, the correct magnitude of the shadow wage - and its relationship to the market wage - have remained controversial. The earliest studies on shadow wages focussed on rural unemployment (open or disguised) in LDCs, and inferred from this that the opportunity cost of hiring new industrial workers was low. Sen (among others) though agrecing that the opportunity cost - in the sense of forgone output - might be low, contended that the shadow wage might nonetheless be high; wage payments to additional workers required diverting resources from (relatively more valuable) investment to consumption. If investment was very valuable, then the shadow wage equaled the market wage.

This view, in turn, was criticized by Harberger and Stiglitz for ignoring the induced migration of agricultural workers to the industrial sector. If the workers earned fixed wages in the two sectors, then under the Harris-Todaro hypothesis that the expected wage in the industrial sector equals the agricultural wage, they showed that the shadow wage was equal to the market wage, regardless of the relative social valuation of investment. These earlier studies thus identified two of the important determinants of the shadow wage - the nature of intertemporal trade-off and endogenous migration.

In this paper, we present a framework for shadow wage determination which, while incorporating the above issues, deals explicitly with many salient features of LDCs which are important but have not received the attention they deserve. These include: (i) the differences between domestic and international prices, (ii) the equilibrating mechanisms in the economy which determine, for example, whether the general equilibrium impact of industrial employment creation is to increase the relative price of the agricultural good or to increase its net import, (iii) the mechanisms which determine the distribution of earnings within agricultural and industrial sectors, and (iv) the consequences of industrial employment creation on those who remain in the agricultural sector, for example, through what we identify as congestion effects. Many of these aspects have first order effects on the magnitude of shadow wage; to ignore them would lead to misleading results.

Our method has been to identify those reduced form relationships for describing the economy which are central to the determination of shadow 
wage. We have shown how the same reduced form relationship (and hence the same formulae for the shadow wage) can be specialized to different technological assumptions (e.g. the nature of production relationships in the agricultural and industrial sectors) and institutional settings, as well as to different behavioral hypotheses. For example, our formulae for the shadow wage contain certain critical elasticities which can be specialized to alternative migration hypotheses (including the Harris-Todaro case) and to alternative hypotheses concerning wage determination (including those based on the wage-productivity and the labor turnover effects).

This method has the virtue of analytical simplicity because it provides an integrated view of the critical determinants of the shadow wage. We have, therefore, been able to derive earlier results on shadow wages as special cases of our formulae. Also, we have identified a number of new qualitative results concerning the relationship between the shadow wage and the market wage.

There are several limitations of our analysis which we have pointed out in the paper. In particular, we have examined only a limited set of rigidities; we have not considered, for example, the possibility that markets other than that for labor may not clear. Also, our models of migration and the determination of workers' wages and earnings are essentially static. It is possible, for example, that the brunt of the effects of employment creation in one period are felt in the future.

Also, we have abstracted from the issues concerning savings and the alleged scarcity of capital in LDCs. In this case, one needs to identify whether there is any market failure, other than a possible divergence between the intertemporal distribution of welfare generated by the market and that preferred by the social planner. Furthermore, how individuals adjust their savings behavior to the government's action may depend critically on the source of the alleged market failure; for example, on the nature of problems associated with imperfect information and contract enforcement which might be responsible for the market failure. This, in turn, may have a bearing on the magnitude of the shadow wage.

\section{References}

Bale, M.D. and E. Lutz, 1979, Price distortions in agriculture and their effects: An international comparison, World Bank Staff working paper no. 359, Washington, D.C.

Benassy, J.P., 1975, Neo-Keynesian disequilibrium in a monetary economy, Review of Economic Studies 32, 503-523.

Bliss, C. and N. Stern, 1978, Productivity, wages and nutrition, Journal of Development Economics 5, 331-398.

Blitzer, C., P. Dasgupta, and I.F. Stilglitz, 1981, Project appraisal and foreign exchange constraints, Economic Journal 91, 58-74.

Diamond, P.A. and J.A. Mirrlees, 1971, Optimal taxation and public production I: Production efficiency, and II: Tax rules, American Economic Review 61, 8-27 and 261-278.

Dixit, A.K., 1968, Optimal development in the labour-surplus economy, Review of Economic Studies 35, 23-34. 
Dixit, A.K., 1971, Short-run equilibrium and shadow prices in a dual economy, Oxford Economic Papers 23, 384-400.

Dixit, A.K. and N. Stern, 1974, Determinants of shadow prices in open dual economies, Oxford Economic Papers 26, 42-53.

Harberger, A., 1971, On measuring the social opportunity cost of labor, International Labor Review 103, 559-579.

Harris, J.R. and M.P. Todaro, 1970, Migration, unemployment and development: A two sector analysis, American Economic Review 60, 126-142.

Heady, C.J., 1981, Shadow wages and migration, Oxford Economic Papers 33, 108-121.

Khan, M.A., 1980, The Harris-Todaro hypothesis and the Heckscher-Ohlin-Samuelson trade model, Journal of International Economics 10, 527-547.

Little, I.M.D. and J.A. Mirrlees, Manual of industrial project analysis in developing countries, Vol. II, Social cost benefit analysis, Development Center of the Organization for Economic Co-operation and Development, Paris, 1968.

Malinvaud, E., 1977, The theory of employment reconsidered, Basil Blackwell, Oxford.

Marchand, M., J. Mintz and P. Pesticau, 1983, Public production and shadow pricing in a model of disequilibrium in labor and capital markets, Mimeo, CORE Discussion Paper No. 8315, CORE, Louvain-la-Neuve.

Mirrlees, J.A., 1983, Market prices and shadow prices, Mimeo, Nuffield College, Oxford.

Newbery, D.M.G., 1972, Public policy in the dual economy, Economic Journal 82, 567-590.

Newbery, D.M.G., 1974, The robustness of equilibrium analysis in the dual economy, Oxford Economic Papers 26, 32-41.

Peterson, W.L., 1979, International farm prices and the social cost of cheap food policies, American Journal of Agricultural Economics 61, 12-21.

Roberts, K., 1982, Desirable fiscal policies under Keynesian unemployment, Oxford Economic Papers 34, 1-22.

Sah, R.K., 1982, Performance of coupon, queues and rations in managing scarcities, CADE Discussion Paper 82-48, Department of Economics, University of Pennsylvania, Philadelphia.

Sah, R.K. and J.E. Stiglitz, 1983, The town, the country and the rest of the world: Economics of public marketing boards in developing countries, Mimeo, Department of Economics, Princeton University, Princeton.

Sah, R.K. and J.E. Stiglitz, 1984a, The economics of price scissors, American Economic Review $74,125-138$.

Sah, R.K. and J.E. Stiglitz, 1984b, Taxation and pricing of agricultural and industrial goods, Working paper no. 1338, National Bureau of Economic Research, Cambridge. Forthcoming in: D.M.G. Newbery and N.H. Stern, eds., The theory of taxation for developing countries.

Sen, A.K., 1968, Choice of techniques, Blackwell, Oxford.

Sen, A.K., 1972, Control areas and accounting prices: An approach to economic valuation, Economic Journal 82, 486-501.

Solow, R.M. and J.E. Stiglitz, 1968, Output, employment and wages in the short run, Quarterly Journal of Economics 82, 537-560.

Srinivasan, T.N. and J.N. Bhagwati, 1978, Shadow prices for project selection in the presence of distortions: Effective rates of protection and domestic resource costs, Journal of Political Economy 86, 97-116.

Stern, N.H., 1972, Optimum development in a dual economy, Review of Economic Studies 39, 171-184.

Stiglitz, J.E., 1971, Alternative theories of the determination of unemployment and wages in L.D.C.'s, Mimeo, Institute for Development Studies, University of Nairobi.

Stiglitz, J.E., 1974, Alternative theories of the determination of wages and employment in L.D.C.'s-I. The labor turnover model, Quarterly Journal of Economics 88, 194-227.

Stiglitz, J.E., 1982a, The structure of labor markets and shadow prices in L.D.C.'s, in: Sabot, R.H., ed., Migration and the labor market in developing countries, Westview Press, Colorado.

Stiglitz, J.E., 1982b, Alternative theories of wage determination and unemployment: The efficiency wage model, in: Mark Gersovitz, et al., eds., The theory and experience of economic development, George Allen and Unwin, London.

Stiglitz, J.E. and P.S. Dasgupta, 1971, Differential taxation, public goods and economic efficiency, Review of Economic Studies 38, 151-174. 